\title{
Mecanismos de ação de himenópteros parasitóides sobre Megastes spp. (Lepidoptera: Pyralidae) em agroecossistema de batata-doce (Ipomoea batatas L.)
}

\author{
Attack of parasitoids himenoptera on Megastes spp. (Lepidoptera: Pyralidae) \\ in sweet potato agroecossystem \\ Paulo Alves Wanderley ${ }^{1}$ Maria José Araújo Wanderley ${ }^{2}$ \\ Marcos Barros de Medeiros $^{3}$ Antônio Fernando de Souza Leão da Veiga ${ }^{4}$
} \begin{abstract}
Estudaram-se a presença e a ação de himenópteros
parasitóides em agroecossistema de batata-doce (Ipomoea batatas RESUMO L.) no município de Pedra de Fogo - PB, sobre o complexo Megastes spp, com o objetivo de identificar as espécies de parasitóides existentes, bem como descrever os principais eventos na ação de parasitismo sobre Megastes grandalis Guenee e Megastes pusialis Snellen. No levantamento direto, em $14 \%$ das plantas, existiam fêmeas de microhimenópteros ectoparasitóides da família Braconidae atacando lagartas de Megastes spp. No levantamento indireto, constatou-se um ataque de parasitóide em $22 \%$ das lagartas, emergindo adultos de sete espécies das famílias Braconidae, Chalcididae e Ichneumonidae, com predominância de braconídeos ectoparasitóides. Concluiu-se que a presença de parasitóides no agroecossistema da batata-doce é bastante diversificada e proporcionam uma boa contribuição na mortalidade natural da praga.
\end{abstract}

Palavras-chave:insecta, controle biológico, Bracon.

\section{ABSTRACT}

The presence and action of Hymenoptera parasitoids in agroecossystems of sweet potato (Ipomoea batatas L.) in Pedra de Fogo county - PB, Brazil, on Megastes spp. complex were studied, with the objective of identifying parasitoids species and to describe the main aspects on parasitism action on Megastes grandalis Guenee and Megastes pusialis Snellen. On direct evaluation 14\% of plants had females of ectopasitoids belonging to the Braconidae family. The indirect evaluation showed the occurrence of $22 \%$ of worms attacked by parasitoids. The emergence of parasitoids adults of seven species belonging to the Braconidae, Chalcididae and Ichneumonidae families has been observed. It was concluded that the presence of parasitoids in sweet potato agroecossystem is diversified and important to suppress the insect pest.

Key words: insecta, biological control, Bracon
A batata-doce é uma importante alternativa econômica para pequenos produtores em todo o país. É uma planta altamente nutritiva, constituindo-se em excelente fonte de nutrientes e de energia, sendo comparada ao arroz em nível mundial (HALL \& PATAK, 1993). Apresenta alta rusticidade, fácil adaptação, alta tolerância à seca, fácil cultivo e baixo custo de produção. No Brasil, é a segunda hortaliça mais cultivada, sendo o Rio Grande do Sul o maior produtor. A utilização de parasitóides no controle das pragas que atacam as raízes tuberosas é uma alternativa de controle que precisa ser estudada e poderá ser de grande valor para o melhor equilíbrio de uma produtividade mais elevada. Os parasitóides são muito efetivos em prevenir crescimentos populacionais de pragas (PRICE, 1984). O uso de parasitóides no manejo de pragas em agroecossistemas de algodão no Nordeste do Brasil, por exemplo, vem se mostrando bastante promissor (WANDERLEY \& RAMALHO, 1995). O estudo dos mecanismos de ataque de parasitóides sobre seus hospedeiros é de fundamental importância para se avaliar a viabilidade do uso desses inimigos naturais em qualquer programa de manejo integrado de pragas. Existe, no entanto, uma pequena quantidade de informações sobre a paralisação de hospedeiros, por Braconidae (WHARTON, 1993) e outras famílias de himenópteros parasitóides. É, portanto, necessária a realização de trabalhos que procurem caracterizar os mecanismos de ataque de himenópteros parasitóides em agroecossistemas

\footnotetext{
${ }^{1}$ Professor Doutor em Agronomia E3, Universidade Federal da Paraíba (UFPB), Centro de Formação de Tecnólogos (CFT), Departamento de Agropecuária (DAP), Rua Antônio Alves da Rocha, 12, Conj. Edgar Sta Cruz, 58220-000, Bananeiras, PB. E-mail: alwanderley@iwpb.com.br. Autor para correspondência.

${ }^{2}$ Doutor Agronomia, Bolsista Desenvolvimento Regional, CNPq-UFPB

${ }^{3}$ Professor Doutor, Adjunto IV, UFPB, CFT, DAP.

${ }^{4}$ Professor Doutor Adjunto IV, Departamento de Biologia, Universidade Federal Rural de Pernambuco.
} 
específicos. O trabalho teve como objetivos identificar as famílias de parasitóides existentes em agroecossistemas de batata-doce e descrever os principais eventos na ação de parasitismo sobre Megastes grandalis Guenee e Megastes pusialis Snellen, duas brocas que atacam as hastes da planta.

A primeira etapa do trabalho foi desenvolvida a campo, na Fazenda Gramame, no município de Pedra de Fogo, PB, ano agrícola de 2002, em área de plantio de batata-doce medindo $2500 \mathrm{~m}^{2}$, sob UR de 50,0 $\pm 2,0 \%$, durante as observações e coletas, as quais ocorreram entre $9 \mathrm{~h}$ e $14 \mathrm{~h}$. Para o levantamento da ocorrência de himenópteros parasitóides, foram escolhidas 50 plantas ao acaso, em caminhamento zigue-zague. Inicialmente, fez-se um levantamento direto, visando detectar a presença e coletar fêmeas de parasitóides em oviposição nas hastes atacadas pela broca, para posterior identificação taxonômica. Posteriormente, efetuou-se o levantamento indireto, a fim de definir uma amostragem de mesmo tamanho e com o mesmo método de distribuição, coletando-se 50 segmentos de hastes de plantas com sintomas do ataque da broca, escolhidas ao acaso.

Esses segmentos atacados foram conduzidos ao Laboratório de Entomologia do Departamento de Biologia da UFRPE-Recife onde, em uma segunda etapa do trabalho, cada segmento de haste foi dissecado, a fim de se identificar a presença de pupas, nuas ou em casulos, de himenópteros parasitóides. As hastes que continham lagartas paralisadas e/ou presença de pupas de parasitóides, foram colocadas em uma caixa de emergência, enquanto as hastes que continham lagartas ativas foram colocadas em outra caixa de emergência, com o objetivo de separar a emergência de adultos de ectoparasitóides na primeira caixa, da emergência de adultos de endoparasitóides na segunda caixa.

Os resultados do levantamento direto no intervalo mostraram que, em $14 \%$ das plantas, existiam fêmeas de microhimenópteros ectoparasitóides da família Braconidae atacando lagartas de Megastes spp. Após a detecção das lagartas hospedeiras, as fêmeas de braconídeos introduzem o ovipositor através da haste da planta, e, após reconhecer o hospedeiro, injetam veneno paralisante suficiente para imobilizar a lagarta, a qual fica passiva de receber os ovos do parasitóide. Comportamento semelhante foi observado por WANDERLEY et al. (1999). Posteriormente, verificou-se, através das formas jovens, que esse é o comportamento de fêmeas das espécies cujas larvas são ectoparasitóides.
O exame das hastes de batata-doce no laboratório permitiu constatar a presença de pupas de parasitóides em $22 \%$ delas, todas envolvidas por casulos de aspecto cotonoso e coloração branca. Uma média de 2,73 $\pm 0,69$ casulos haste ${ }^{-1}$ atacada foi encontrada, emergindo adultos na primeira caixa, de três espécies diferentes de ectoparasitóides, sendo duas espécies pertencentes às famílias Braconidae (Bracon sp. e B. vulgaris Ashmead) e uma espécie pertencente à família Ichneumonidae. Espécimes dos adultos desses parasitóides foram enviados a especialistas para identificação.

As larvas de ectoparasitóides se alimentam externamente de fluídos extravasados do corpo do hospedeiro através de ferimentos feitos pelo aparelho mastigador. Após o estágio larval, surgem as pupas protegidas por casulos cotonosos que permanecem ao lado dos restos da lagarta hospedeira, até a emergência do adulto. Quanto aos parasitóides, emergiram quatro espécies sendo três pertencentes às famílias Chalcididae e uma espécie pertencente à família Braconidae. A fase larval da espécie da família Braconidae desenvolveu-se dentro do corpo da lagarta, sendo que as pupas se formaram externamente protegidas em casulos cotonosos. As três espécies de Chalcididae desenvolveram as fases larval e de pupa no interior do corpo do hospedeiro, emergindo os adultos a partir da pupa do hospedeiro. Com os resultados obtidos, concluiu-se que a presença de himenópteros parasitóides no agroecossistema de batata-doce é bastante diversificada, sendo os braconídeos encontrados em maior abundância em relação aos demais parasitóides.

\section{REFERÊNCIAS BIBLIOGRÁFICAS}

HALL, M.R.; PHATAK, S.C. Sweet potato Ipomoea batatas (L.) Lam. In: KALLO, G.; BERG, B.O. Genetic improvement of vegetable crops. New York : Pergamon, 1993. p.693-708.

PRICE, P. Insect ecology. New York : John Wiley, 1984. 604p.

WANDERLEY, P. A.; RAMALHO, F. S. Biologia e exigências térmicas do Catolaccus grandis (Hymenoptera: Pteromalidae) parasitóide do bicudo, Londrina, PR, 1995. In: REUNIÃO NACIONAL DO ALGODÃO, 8., 1995, Londrina. Resumos... Londrina : IAPAR, 1995. p. 95.

WANDERLEY, P.A. et al. Impacto da temperatura na reprodução de Bracon vulgaris Ashmead (Hymenoptera:Braconidae), parasitóide do bicudo-do-algodoeiro. Ribeirão Preto, SP, 1999. In: SEMINARIO INTERNACIONAL DEL PROYETO: "MANEJO INTEGRADO DEL PICUDO DEL ALGODONEIRO EM ARGENTINA, BRASIL Y PARAGUAY" 1999, Ribeirão Preto. Programa y Resúmenes... CFC-ICAC/04, 1999. p.23-24.

WHARTON, R.A. Bionomics of the Braconidae. Annual Review of Entomology, Palo Alto, v.38, p.121-143, 1993. 